\title{
Espiritual e magia na arte. A noção de Gênio na obra de Kandinsky
}

\author{
Walter Menon \\ romeromenon@yahoo.fr \\ Universidade Federal do Paraná (UFPR), Curitiba, Brasil
}

resumo Este texto pretende-se um ensaio sobre a questão do Espiritual na teoria pictórica de Kandinsky. Nele busco evidenciar a ideia de que as concepções do pintor russo, em grande parte construída em consonância com o pensamento esotérico do fim do século XIX, aproximam-se bastante de um tipo de cosmologia mágica, que abriga uma perspectiva análoga àquela das categorias do pensamento mágico segundo Marcel Mauss. No centro desta cosmologia encontra-se a arte, síntese do Espiritual, cuja noção central é a de gênio que creio ser herdada em grande medida de Kant.

palavras-chave arte espiritual; gênio; cosmologia; Kandinsky; Mauss; Kant

Este texto se pretende uma análise da noção de espiritual apresentada na obra teórica de Kandinsky, sobretudo em Do Espiritual na Arte e na Pintura em Particular, entendendo-a como princípio estético e moral. Princípio este que estaria ligado, antes de tudo, à ideia de uma ordem sobrenatural inspirada pela leitura de Kandinsky das obras de Madame Blawatsky e que constitui o eixo teórico de sua obra escrita. Acredito que, em grande medida, o texto de Kandinsky, ao se apoiar nas concepções místicas exotéricas de Blawatsky, constitui-se em uma visão arcaizante da arte que se define como parte de uma cosmologia mágica. O termo mágico aqui,penso-o de acordo com as categorias elaboradas por Marcel Mauss, para quem o pensamento mágico seria constituído por modos tradicionais de organização social que nos ritos mágicos suprimem o diferente. Tal qual nos ritos de incorporação, pensados por Mauss, em Kandinsky a 
arte se estabelece em, ao mesmo tempo que instaura, pontos de passagem constitutivos de um universo organizado hierarquicamente de acordo com leis "mágicas".

Central nessa ordem mágica, para Kandinsky, e intrínseca ao espiritual que reflete a obra de arte abstrata, encontrar-se-iam duas outras noções: a de gênio e a de talento. Verifica-se, como de resto já se havia apresentado na tradição filosófica desde Kant, que essas duas noções sinônimas, representam o elemento da natureza que dota a arte de regras. Dessa maneira, pretendo mostrar como a questão do espiritual na arte surge sob o duplo signo das concepções mágicas do mundo em consonância com a noção de gênio. Acredito que tais noções são de suma importância para se compreender a questão do espiritual na arte, não só em Kandinsky, mas em toda uma tradição em artes plásticas que daí derivará um discurso e uma prática que reivindica a desmaterialização progressiva do objeto plástico como instância fundamental do fazer artístico. A ordem espiritual encontra-se conexa a uma certa noção do primitivo, relacionado à magia, e consiste no fundamento teórico da abstração pictórica. Se por um lado a arte abstrata se apresenta em oposição a tudo o que é representação da natureza, entendida como os objetos externos à própria linguagem formal da arte, por outro, o abstracionismo, do tipo que tem em Kandinsky seu representante, busca incorporar a natureza na arte não como objeto, mas como procedimento que tem em uma forma arcaica de espiritualidade sua materialização. $O$ pintor acadêmico que quisesse expressar o estado de espírito de uma paisagem, pintava a própria paisagem, já o pintor abstrato buscava transformar este estado de espírito em obra. São projeções desse estado de espírito na materialidade da obra. No segundo caso, a pintura é efeito de um estado de ânimo. Este, por sua vez, é regido por uma faculdade do espírito que obedece a regras de uma natureza que em grande medida interna ao artista, reflete, não obstante, a ordem invisível do cosmos.

Kandinsky pretende dar uma justificativa metafísica e moral ao abstracionismo em artes plásticas, no sentido de apresentá-lo como, não só uma libertação das fórmulas tradicionais da figuração, sobretudo em pintura, mas também como resposta a uma estética da materialidade. Baseado em uma concepção mágica do mundo, ele procura romper com fórmulas consideradas índices de uma civilização materialista decadente. A metafisica de Kandinsky tomará, portanto, a forma de um pensamento místico e 
mágico, arcaico e arcaizante da experiência estética, traduzida na concepção de espiritual. O espiritual que aparentemente significaria uma ultrapassagem do gosto e arte decadentes, regidos pela figuração, e valorização da matéria, preserva, paradoxalmente, em noções tais quais as de talento, gênio, etc., elementos e conceitos que pertencem a etapas anteriores, na história da arte, àquela em que Kandinsky elabora seu pensamento. Por outro lado essas noções são atualizadas, no texto e na produção artística de Kandinsky a partir de doutrinas espiritualistas portadoras de uma concepção de mundo religiosa heterodoxa, onde se misturam elementos cristãos e de outras religiões.

As manifestações, figurações do espírito na obra de arte encontram suasformulações condensadas em sua obra principal: Do espiritual na arte e na pintura em particular. O que impressiona no texto de Kandinsky é mais a “desencarnação", ou a desmaterialização da visão pelo encantamento da palavra, que propriamente sua tentativa de fundar as bases formais da pintura abstrata a partir de uma pretendida experiência espiritual inerente à abstração. Ainda que as duas coisas não estejam dissociadas em Kandinsky - a abstração da pintura não pode se fazer sem sua "desmaterialização", isto é, sem o abandono, não somente da representação figurativa, mas também da expressividade material da pintura, - é justamente a palavra que permite a desencarnação da obra, quer dizer que permite à subjetividade do artista, pressuposta representada na obra, tornar-se subjetividade absoluta. Dito de outra maneira, pela palavra interposta, se experimenta o "corpo" limitado da pintura, no sentido da sua singularidade de objeto que se oferece ao espectador, como o "corpo glorioso" da experiência estética da unidade entre forma e materialidade na abstração, concebida em analogia com a experiência mística. Essa unidade se traduz pela visão transcendente, onipresente do espiritual. Posto que despojada de todo limite de espaço e tempo singulares, o espiritual na arte torna-se experiência estética instaurada pelas formas absolutas da abstração que se substitui àquela outra do limite sensível do espectador.

Exercício de ascese, cujo objetivo é justamente a elevação da vida humana ao estado de pura ideia, puro conceito, a arte abstrata concebida por Kandinsky contém um apanhado de prescrições e invocações que devem ser respeitadas e seguidas pelo espectador a fim que ele possa reconhecer sua própria visão purificada do peso ilusório da corporeidade figurativa. 
Ora esta "purificação" se consuma apenas quando o espectador não pode se impedir de ver, nas formas articuladas da composição, a imagem do espiritual absoluto: a imagem de uma intencionalidade sem intenção, ou melhor, a imagem de "uma finalidade sem fim" no sentido kantiano. Assim, a abstração primeira é aquela da intenção do artista na intencionalidade do espiritual encarnado na obra. A forma visual torna-se livre jogo, linguagem autônoma, desprovida de um corpo, de um enunciador. A partir deste gesto subjetivo do autor que se torna subjetividade absoluta, o espectador pode se deixar levar pela experiência visual à qual ele deve aderir identificando-se com a intenção suposta do artista transformada por sua vez em manifestação do espiritual.

Pode-se então conceber a composição visual, que se quer objetiva na sua apresentação, como sendo a representação da concepção teórica da abstração visual expressa pelo artista. Assim, Kandinsky abre seu ensaio do espiritual na arte atacando o primado da imitação, para reabilitá-lo a sua revelia. Ele refaz o caminho já trilhado por diversas versões do platonismo que é o de colocar em questão não a imitação em si, a ação de imitar, mas a legitimidade daquilo que deve ser imitado. Isto do ponto de vista da sua constituição ontológica. No seu empreendimento de purificação da arte, é necessário, antes de qualquer coisa, definir o que não deve ser objeto de imitação, a fim de se determinar qual é a boa mímesis. Para Kandinsky, este objeto a ser evitado é o "modelo clássico", cuja referência é a representação idealizada da arte grega (KANDINSKY, 1996).

Mais radical que a condenação do artista por Platão, Kandinsky compara aquele que busca copiar a imitação da arte grega a um símio que imita o comportamento humano (KANDINSKY, 1996). Sua mímica não teria nenhum significado interior; dito de outra maneira, ela estaria desprovida de espírito, isto é desta dimensão não evidente, única capaz de sustentar, fora o aspecto visual e material do gesto, seu sentido. Ora justamente, por que o símio imita sem conhecer o sentido do que ele imita, ele repete mecanicamente os gestos sem imitar-lhes a intenção. Ainda que sem finalidade, apenas a intenção porta o significado da obra. Significação profunda, cuja única possibilidade de acesso se encontra em uma arqueologia idealizada de um tipo, também idealizado, de mímesis. Este tipo,é necessário procurá-lo no primitivo, ou melhor, entre aqueles que o representam no imaginário ocidental, mais precisamente, procurá-la nos 
símbolos de forças inconscientes originárias, das quais testemunham os mitos, e que são, por sua vez, entendidas como forças da natureza. Estas forças seriam aquelas que determinam a essência comum entre individuo, comunidade e a natureza. São forças centrípetas e centrífugas que habitam todos os homens, à medida que são seres sociais e biológicos, e das quais alguns estariam separados desde há muito tempo pela domesticação que operou o processo civilizatório. Ainda que esta separação seja um produto da cultura, é por intermédio de uma pratica cultural, a arte, que se pode aceder a esta ordem primordial. Faz-se necessário recuperar pela arte a experiência do contato com essas forças e as trazer, ainda uma vez, ao centro da vida, porque elas constituem, segundo Kandinsky, a "necessidade fundamental", essa espécie de principio estruturante de uma "ordem cósmica" que ele chama de espiritual, ou "o Essencial interior" e que se encontra refletida na ordem da composição pictórica abstrata.

Existe outra analogia, entre as formas de arte, baseada numa necessidade fundamental. A similitude das tendências morais e espirituais de toda uma época, a busca de objetivos já perseguidos em sua linha essencial, depois esquecidos, e, portanto, a semelhança do clima interior, podem logicamente levar ao emprego de formas que, no passado, serviram com êxito às mesmas tendências. Assim nasceu, pelo menos em parte, nossa simpatia e nossa compreensão pelos primitivos, a afinidade espiritual que descobrimos ter com eles. Como nós, esses artistas puros só se ligaram, em suas obras, à essência interior, sendo por isso mesmo eliminada toda e qualquer contingência. (KANDINSKY, 1996, p. 27)

As formas de arte autênticas seriam, portanto, aquelas que obedecem a uma necessidade interna de afinidade entre os elementos formais que as constituem. Além disso, essa necessidade deve ser similar às leis de afinidade que regem a vida moral e espiritual característica das relações sociais nas sociedades não contaminadas pela "filosofia materialista"; denominação geral dada por Kandinsky às doutrinas que afirmam a contingência, o efêmero, em detrimento da permanência, da conservação.

As formas autênticas da arte, por outro lado, colocariam em relevo as tendências dos "artistas puros", quer dizer, daqueles que procuram fazer de seus gestos fórmulas de conjuração da exterioridade contingente, preservando, assim, sempre os mesmos gestos figurados nas obras de arte 
como “o Essencial interior". Nesse sentido, parece estar sugerido aqui uma certa analogia com o pensamento arcaico do ritual mágico. Analogia entre o gesto do artista e as formulas mágicas de conjuração das forças sociais antagônicas de exclusão e inclusão social, da maneira como foram pensadas pelo antropólogo Marcel Mauss, isto é, como aspectos da reiteração coletiva típica dos ritos mágicos. No gesto do artista, tal qual naquele que instaura o ritual mágico, estariam contidos elementos capazes de harmonizar as forças centrípetas (de preservação, conservação e integração) e as centrífugas (de exclusão, eliminação e marginalização). Forças essas sintomáticas dos modos tradicionais de organização social e figuradas nos ritos mágicos de incorporação, entendida como supressão do diferente.

Os ritos mágicos, e a magia como um todo, são, em primeiro lugar, fatos de tradição. Atos que não se repetem não são mágicos. Atos em cuja eficácia todo um grupo não crê, não são mágicos. A forma dos ritos é eminentemente transmissível e é sancionada pela opinião. Donde se segue que atos estritamente individuais, com as praticas supersticiosas particulares dos jogadores, não podem ser chamadas de mágicas.

(MAUSS, 2003, p. 56)

O que caracterizaria a arte, nesse sentido, parece ser uma busca por recuperar o poder mágico, como descrito por Mauss. Poder que, em um certo sentido, a arte nunca teria perdido, posto que, sua formulação recorrente teria de algum modo, conservado algo do ato de magia. Recuperar este poder de encantamento significaria, portanto, reencontrá-lo atualizado na unidade entre o gesto do artista e o formalismo plástico da pintura, identificados que estão à dimensão transcendental da abstração.

Duas conclusões são aqui possíveis. A primeira é a de que a arte seria o lugar de uma experiência comum, onde são necessárias pelo menos duas instâncias para que haja transmissibilidade, troca de signos, capazes de estabelecer um campo de experiência estética de identificação mútua entre os membros de uma comunidade. A segunda conclusão diz respeito a um reconhecimento, por ambas instâncias, de uma dinâmica de linguagem: aquela do encantamento mágico identificado com a pintura.Têm-se aqui o equivalente ao efeito produzido pela invocação mágica. O encantamento se concretiza apenas quando há o consentimento em aderir à palavra mágica, reconhecendo-se, assim, o sujeito como submetido às leis 
de encantamento manifestas na invocação. Por meio de seu efeito mágico a arte provoca um refinamento da experiência sensorial e da sensibilidade corrompida do homem civilizado, libertando-o do peso de sua materialidade. Ela cumpre um papel moral. A repetição do protocolo da abstração plástica, nas obras, corresponde àquela da fórmula de encantamento. Há como que uma purificação, uma espiritualização das formas de figuração da arte, que, ao se abstraírem, provocam, por sua vez, o despertar de um tipo de experiência em que pressupõe uma ascensão espiritual contínua, representada por uma hierarquia de sentimentos que vai do mais material, arte figurativa, até o espiritual abstrato, numa correspondência clara com uma purificação dos sentimentos morais.

Os sentimentos elementares, como o medo, a tristeza, a alegria, que teriam podido, durante o período da tentação, servir de conteúdo para a arte, atrairão pouco o artista. Ele se esforçará por despertar sentimentos mais matizados, ainda sem nome. O próprio artista vive uma existência completa, relativamente requintada, e a obra, nascida de seu cérebro, provocara, no espectador capaz de experimentá-las, emoções mais delicadas, que nossa linguagem é incapaz de exprimir. (KANDINSKY, 1996, p. 28)

Kandinsky, dessa maneira, alude ao efeito da magia estética sobre o espectador que o livra do peso de um olhar carregado pelos artifícios ilusórios da tradição da representação visual do Ocidente, representada pelo naturalismo da pintura figurativa. Os esquematismos culturais, tais quais, a perspectiva em pintura, contaminaram durante séculos o olhar antes puro, limitando a visão à exterioridade de um mundo de simulacros que se substituem à imagem real, quer dizer, àquela que a ação cirúrgica da abstração torna visível, recuperando, assim, a inocência de um olhar original, primitivo. Esta "visão da alma" seria antes de tudo da ordem de um sentir a presença de uma "vibração": algo que nos envolve, o ambiente, e nos é sempre invisível (KANDINSKY, 1996).

A ambiência espiritual da arte, por um efeito de consonância/dissonância se transmite ao espectador; reproduz nele um estado de alma inteiramente idêntico à ambiência produzida na pintura. Para que se possa participar de uma tal harmonia, é suficiente aceitar como necessário o fato de que há uma outra alma, a do artista, que goza de uma espiritualidade 
essencialmente indiferenciada daquela do espectador. Mas para que haja tal reconhecimento faz-se necessário "educar o espectador a fim de lhe elevar ao nível do artista” (KANDINSKY, 1996, p. 29). Nível este em que o artista é tão somente pura espiritualidade, despojada de peso de todo limite imposto por sua individualidade e, portanto, exaurida de toda necessidade que não seja ideal; dito de outra maneira, que não seja outra que aquela representada na ordem de uma necessidade intrínseca à composição abstrata. Ordem essa que reproduz aquela outra das formas elementares da estrutura do real.

Percebe-se, portanto, que o modelo reprodutivo se conserva, isto é, aquele que caracteriza a figuração e condena a obra à escala mais elementar, sensorial da experiência do real. Não obstante, sua permanência encontra-se dissimulada na experiência de ascese, de purificação do olhar, pela mímesis da Visão elevada, resultante da ordem dos elementos formais que compõem uma tal Visão espiritual. Por conseguinte, na condição de iniciado nos mistérios da arte, bem como naqueles da ordem oculta do mundo, o artista teria por finalidade iniciar, por sua vez, o espectador nesses mistérios, fazendo-o gozar, na contemplação da ordem formal da pintura abstrata, da visão da ordem essencial do mundo. A ação da magia estética se faz sentir pelos efeitos "simpáticos" das fórmulas encantatórias da abstração pictórica, que faz de tal abstração o lugar da apresentação da ordem do mundo.

Para Marcel Mauss a magia se transmite por um tipo de relação de afinidade dita simpática, mas que envolve também seu inverso: o elemento da antipatia. Esta afinidade obedece, entretanto, a uma ordem de associação entre os elementos em jogo determinada pela partilha entre eles de dois ou mais atributos que indiquem relação de similaridade (MAUSS, 2003). Tal experiência apontaria para a evidência de algo comum, algo que é o mesmo e determinante para todos os elementos que são atravessados pelo encantamento mágico. Três seriam as leis que regem a transmissão da magia: a de contigüidade, de similaridade e a de contraste. Haveria, portanto, uma sobreposição entre as leis das associações entre pensamentos e as relações causais entre as coisas materiais. Pode-se verificar, seguindo as ideias de Mauss, como as relações entre os elementos formais em uma pintura abstrata obedecem no texto de Kandinsky às mesmas leis da magia. As leis de associação de pensamento são as mesmas da composição abstrata, 
isto é espelham uma ordem cósmica. As formas e as cores se unem e se contrastam em uma harmonia e em uma escala de valores formais e cromáticos inteiramente regida por ritmos e tonalidades que constituem, em última análise, relações de similitude, contiguidade e contraste. Sendo que contiguidade e similitude podem ser traduzidas como as afinidades entre elementos formais e cores que unem em um todo as partes da composição. Essas relações espelham necessariamente as outras intrínsecas à ordem formal, ou melhor, ideal do mundo. Assim como a abstração pictórica tem em seu fundamento a composição de formas geométricas elementares, segundo um esquema emprestado à tradição do platonismo, regida por leis de afinidades e contrastes, assim também, em sua essência espiritual, o real é, basicamente, uma estrutura geométrica.

O universo é estruturado com a forma do triângulo: figura privilegiada pela tradição mágica, esotérica. $\mathrm{O}$ triângulo representa o movimento perpétuo da hierarquia espiritual dos seres. Ele é a essência da distinção que rege os homens. Não percebida pelo conjunto dos indivíduos que constituem sua base, o triângulo de Kandinsky se configura em um movimento resultante do esforço para se passar da base ao vértice indo a uma ascensão progressiva desafiando a desigualdade espiritual da humanidade. Desigualdade provisória, tendo em vista sua dinâmica espiritual, da qual se pode apenas tomar consciência a partir da situação privilegiada daquele que se encontra na sua ponta extrema, isto é a posição do artista. Por conseguinte, o real não se limita aos limites de uma geometria estática, mas antes se constitui em construção com sua própria dinâmica interna de transformação da base em cume.

Lugar solitário por sua topografia espiritual, o ponto extremo do triangulo, seu cume, pressupõe como condição necessária o despertar da consciência espiritual, traduzida na Visão do real em sua totalidade, Visão que consiste em um reflexo do espiritual da abstração. Àquele que conseguiu atingir o ponto mais alto deste triangulo espiritual, cabe revelar aos homens a dessemelhança de suas relações, libertando-os, assim, dos limites impostos por uma "visão" singular, restrita, até mesmo mesquinha de suas próprias vidas. Aquele que já atingiu o despertar espiritual tem por tarefa mostrar aos outros o caminho a ser percorrido para se conquistar este "abrir de olhos" espiritual. Apesar de não ser um privilégio do artista, este é por excelência o caminho por ele percorrido e que aparece figurado na 
nova ordem da pintura abstrata que é necessário seguir, ordem essa musical, invisível e visível, limitada no tempo e no espaço, mas, entretanto, presente de maneira absoluta em tudo, tal qual a ordem cósmica dos pitagóricos.

Por vezes, escreve Kandinsky, na ponta extrema deste triangulo há não mais que um homem solitário (KANDINSKY, 1996). O artista dotado daquela visão que só o talento e a sua consequente ascensão mística podem produzir, é necessariamente isolado na sua tarefa de fazer avançar a humanidade elevando-a de sua condição decadente e materialista. Para Kandinsky há uma relação intrínseca entre o significado do elemento espiritual e o do primitivo na sociedade, assim como na arte. Primitivo teria antes de tudo o sentido de não contaminado pela civilização nos seus aspectos técnico, econômico e social que Kandisnky identifica com o materialismo (KANDINSKY, 1996). Na pureza do primitivo encontra-se o espiritual. $\mathrm{O}$ isolamento, portanto, não é voluntário. $\mathrm{O}$ artista não escolhe por sua genialidade, que lhe permite o acesso ao espiritual, à solidão dos visionários; esta é antes decorrente do fato de que a humanidade resiste à inevitável ascensão que lhe é destinada, e nessa resistência tem por alvo o artista.

Ainda que Kandinsky seja um inovador, não só nas suas pinturas, mas também nas suas concepções teóricas, em muito de suas teses conservam-se concepções das estéticas românticas e de sua herdeira simbolista, sobretudo no que diz respeito ao papel do artista. Este, tal qual na estética romântica tardia, conserva sua destinação de mártir visionário. "Em sua indignação tratam-no de impostor e demente. Assim, em seu tempo Beethoven solitário foi alvo de seus ultrajes" (KANDINSKY, 1996, p. 62). Mas o que vê o artista? Qual o objeto de sua visão espiritual? Certamente a ordem perene da natureza, ordem da totalidade do ser, cujas leis são discerníveis em um trabalho de depuração espiritual que, em grande medida, coincide com aquele da reeducação dos sentidos por meio da abstração em arte.

Faz-se necessário alargar a experiência estética ordinária limitada que é por modelos materialistas, senão sensualistas, projetando esta experiência sobre o horizonte do modelo espiritual da abstração, pois nele se encontra a demonstração da natureza espiritual da matéria pela equivalência entre as leis da composição formal e aquelas da "ordem do cosmos". Uma vez este modelo aceito, basta se deixar impregnar pela experiência estética da 
abstração, para se purificar seus próprios sentidos, levando-os a um estado de sensibilidade espiritual que permite tornar visíveis as leis da natureza figuradas nas leis da pintura abstrata, como leis da visão espiritual que se compartilha com o artista. Este processo se passa em todas as secções do triângulo estrutural do cosmos: "Podem-se descobrir artistas em todas as partes do triângulo. Aquele que, entre eles, é capaz de olhar além dos limites da parte a que pertence é um profeta para os que o cercam. Ele ajuda a fazer avançar a carroça recalcitrante” (KANDINSKY, 1996, p. 35).

$\mathrm{O}$ artista de gênio, não somente, pode ver o que os outros não poderão ver senão muito tempo depois dele, mas também pode transmitir sua visão, fazendo com que se participe desta por meio da palavra compartilhada, palavra que indica, que mostra o que se deve ver. Uma visão, portanto, com vocação universal. É no texto de Kandinsky que essa palavra mágica tem seu lugar. É por ela que se vê, no sentido de compreender, assim como só o artista pode ver, a composição abstrata espelhar a composição do real. Dito de outra maneira, apenas se é capaz de refazer o caminho da experiência da identidade entre a visão e o que é visto na abstração plástica, ao se fazer a abstração de nossos sentidos, entendidos na sua singularidade; isto é, acordando à palavra do artista, a Kandinsky, portanto, o poder de nos fazer experimentar suas concepções da arte e do espiritual como sendo universais. Por intermédio desta mesma palavra, pretenderia talvez Kandinsky, nos ensinar a possibilidade de ver na abstração pictórica, a abstração dos dados sensíveis da percepção, livrando-a assim, de sua referência corporal, quer dizer, espiritualizando-a, o que permitiria discernir as articulações necessárias dos elementos formais, que constituem a estrutura dinâmica do real, daquelas que são falsas, ilusórias, como por exemplo, aquelas da figuração naturalista identifica ao materialismo da civilização ocidental. A abstração torna visível o real como linguagem, no sentido de um agenciamento formal de signos, ao mesmo tempo na obra e na palavra do artista, cuja lógica é baseada nas relações mágicas entre seus elementos.

Aparentemente, o que está em jogo é a capacidade do artista, não de transformar todas as pessoas em seu símile e, portanto, dotadas de talento e visão espiritual, mas sim, seu poder de transmitir, na obra de arte, esta visão como o fim de uma ascese espiritual. Experiência estética por excelência libertária, à medida que assume a tarefa prometida de ser o único 


\section{4}

lugar possível da vida do espírito. Toma-se como condição do olhar, a possibilidade de se vivenciar, no sentido de uma Erfahung, o espiritual na arte abstrata, porque o que diz Kandinsky em seus escritos, sua obra pictórica materializa. Mas só por pertencer ele mesmo a esta classe de seres especiais dotados de talento e visão espiritual que é o artista abstrato. $\mathrm{O}$ que ele intenta nos fazer ver em suas obras é sua visão no sentido místico espiritual. Ela se encontra confirmada na descrição de sua própria experiência do espiritual, vivida enquanto artista e materializada, paradoxalmente, na abstração pictórica, posto que não há outra maneira de transmiti-la. Tal posição solitária e privilegiada do artista no cume do triângulo da existência, capaz de dotá-lo da "visão perfeita", é a que lhe permite descrever sua experiência estética singular com a legitimidade prometida de uma descrição sistemática do real, cuja pretensão à universalidade ontológica é evidente. É ainda a figura do mágico, no sentido de Mauss, que se amalgama àquela do artista e que oferece a possibilidade de tornar-se parte do espiritual a qualquer um que se disponha à experiência estética de se deixar fascinar pela teoria que impregna sua obra.

Quanto à figura do artista, da maneira que Kandinsky o vê: colocado no ponto extremo da ordem ontológica do cosmos, imune até mesmo às leis da contradição, ele mal se diferencia daquela outra figura do mago. Este modelo do artista mago se difunde em diversas correntes da arte ocidental desde o romantismo, passando pelo espiritual abstrato, o delírio surrealista, chegando mesmo à arte contemporânea, materializada no xamanismo de Joseph Beuys. O modelo do visionário, do místico, afetado pelos dons, os "talentos" segundo o termo herdado da estética romântica por Kandinsky, se conserva neste ser de exceção que é o artista capaz ao mesmo tempo de despertar e anestesiar a consciência do espectador, por meio de uma verdade revelada de uma teoria fisica do mundo, que em grande parte se resume a um sistema de pensamento mágico, isto é, uma física determinada não por leis mecânicas, mas para-simpáticas, as mesmas que se encontram mimetizadas na ordem abstrata da pintura.

Assim como a ciência, a pintura para Kandinsky reivindica o poder de descobrir e descrever o universo microscópico e o macroscópico com suas leis matemáticas e formas abstratas, por meio de uma analogia com o sensível objetivado, não na sua representação conceitual, mas sim, na linguagem formal da pintura abstrata. Isto faz com que gozemos dessa 
visão ampliada em paralelo àquela da magia espiritual, que por isso mesmo, atribui à natureza, ao mundo, um princípio teleológico. É necessário, como na ciência, mas para além dos limites lógicos desta, desmaterializar o mundo na linguagem para poder torná-lo visível, palpável, de maneira absoluta. Uma vez transmudado em linguagem, pela linguagem, o mundo surge como o efetivamente sensível comum a toda experiência estética que se determina como único real possível. A analogia entre a ordem do cosmos (o real) e aquela do abstracionismo, delineia as bases do paralelo entre o procedimento do artista mago e o do teórico da ciência (KANDINSKY, 1996).

Ao lado da teoria científica se encontra a teoria artística do mundo, na busca por fazer com que da matéria seja liberta o "espírito cativo" (KANDINSKY, 1996). Kandinsky reclama do mesmo poder da ciência em revelar a estrutura do mundo a partir do que ele crer ser a raiz comum entre arte e ciência, ou seja, o conhecimento revelado aos magos, visionários paranormais (KANDINSKY, 1996). Tal figura e conhecimento encontram-se condensados na mística paranormal russa Madame Blawatsky e em sua doutrina, que em grande medida constitui a fundamentação da cosmologia de Kandinsky. Tal cosmologia reflete, em grande parte, um certo sintoma de regressão a um arcaísmo que acompanha a época moderna, caracterizado de maneira positiva, como alternativa ao decadentismo das instituições identificadas à civilização europeia. O primitivo, o sobrenatural, o patológico são associados a uma natureza não contaminada pela razão científica materialista, bem como a uma certa noção de pureza e verdade; eles são percebidos como índices de uma divergência possível à massificação da razão instrumental produtiva e aos costumes burgueses que lhe são ligados. É a esse estado de coisas que a arte espiritual pretende se contrapor, desafiando a ordem artificial da técnica e da civilização, segundo os termos de Kandinsky. Essa busca por alternativas a um suposto materialismo tecnicista atinge até mesmo o campo da religião. Consideradas como parte dessa decadência da civilização ocidental, as religiões monoteístas são rejeitadas, em proveito de um engajamento por parte de alguns intelectuais e artistas em sistemas esotéricos de fundo orientalista, tais como, a Teosofia de Blawatsky. Há como que uma fascinação por um pensamento mágico no seio mesmo da modernidade, e as concepções teóricas da arte abstrata não escapam ao seu influxo. Muito 
pelo contrário, elas estabelecem seus pressupostos tendo por base a visão de uma ordem mágica essencial que rege todas as coisas e que não contradiz, mas se sobrepõe àquela outra revelada pela ciência.

Nesse sentido, Kandinsky pensa que a arte deve se voltar para o primitivo com a finalidade de redescobrir práticas e métodos de um conhecimento capaz de revelar o invisível e dar uma resposta ao que ele crê ser um ceticismo generalizado ligado às ciências (KANDINSKY, 1996). Ceticismo esse, que teria se instaurado a partir da constatação da insuficiência dos métodos científicos, para dar conta da dimensão não acessível aos sentidos, na qual reside o espiritual do homem e do mundo, a "não-matéria", nos termos de Kandinsky. Como se pode perceber, o espiritual, da maneira como é condensado nas doutrinas esotéricas, não se estabelece em uma contraposição à ciência, ou à matemática. Ele reivindica um lugar de origem e alicerce do pensamento cientifico próximo àquele da tradição filosófica ocidental.

Se por um lado a imagem do artista filósofo e cientista parece ser nada mais que uma atualização na história da arte da figura arcaica do mago, por outro, ao se conceber como este ser de exceção que proporciona a possibilidade de aceder à essência das coisas na linguagem formal do abstracionismo pictórico, o artista, como pensado por Kandinsky, atribui a si mesmo a posição da autonomia perfeita da consciência liberta de se representar como consciência de si. Abre-se uma passagem em direção à experiência maior de um modo de vida original, primitivo e, portanto, espiritual. Modo de vida esse, com o qual o artista se encontra plenamente identificado, à medida que é ele mesmo que promove a experiência estética e mágica de um transe espiritual, no qual, a consciência e a sensibilidade alteradas, encontram-se refletidas nas formas e cores das composições abstratas. Desta maneira, o artista representa na pintura a crença na possibilidade da alienação completa de si na linguagem formal da arte.

Não é sem propósito, portanto, que gostaria de sugerir uma aproximação entre o uso dos termos talento e gênio por Kandinsky em Do espiritual na arte, e o de Kant na Critica do Juízo. Creio ser possível tornar claro nesta aproximação que a concepção de gênio em Kandinsky é fundamental quando se trata de entender o que significa o espiritual na arte. $\mathrm{O}$ espiritual resulta da crença em um pensamento mágico que, por sua 
vez, se pensa em conformidade às regras da abstração e numa relação de analogia com as leis da natureza. A pintura é o lugar da conjunção das regras da natureza e da cultura. $\mathrm{O}$ talento, para Kandinsky, designaria, dessa maneira, a qualidade do artista de tornar visível nas normas da abstração, as leis de uma suposta ordem invisível da natureza. Kant, na Critica do Juízo, havia afirmado a separação entre as regras técnicas que não diferenciam um mero artefato de uma obra, e aquelas do belo. Para que uma obra seja bela, quer dizer, efetivamente obra de arte e não apenas uma reprodução medíocre, ela deve, não apenas ser um artefato resultante da aplicação de regras técnicas, ou seja, algo, cuja forma reflete uma finalidade, mas tem que conter uma série de regras que escapem a toda finalidade determinada pelo uso. Essas são as regras do belo e este, segundo Kant, é necessariamente algo da ordem da natureza, tendo em vista que a forma do belo não reflete uma intencionalidade e não é conforme o conceito, mas sim reflete a finalidade sem propósito, sem fim da natureza. As regras da arte, das belas artes, são as regras do belo, ou seja, dadas pelo Gênio, aquelas da natureza inscritas na arte.

No parágrafo 46 da Crítica do Juízo, Kant define as propriedades do gênio como sendo basicamente três: a primeira se afasta da noção de habilidade de seguir regras, noção derivada da téchne grega, para se afirmar como capaz de produzir sem regras determinadas a priori e, portanto, de maneira original. A segunda diz respeito à capacidade do gênio fornecer regras a si mesmo, uma vez que não segue regras determinadas, mas também de servir de modelo a outras obras. A terceira e a quarta afirma que a regra que o gênio fornece a si mesmo é a natureza, desprovida de conceitos e juízos prévios. Não é um saber próprio ao artista que ignora, por conseguinte, como tais regras encontram-se nele. Ele não pode imaginá-las, nem prescrevê-las. Na etimologia da palavra gênio fornecida por Kant no final do parágrafo, encontra-se indicada sua origem mágica, aquela de uma natureza paradoxalmente sobrenatural, não determinada conceitualmente e que dá regras à arte, mas não à ciência, visto que esta pressupõe o conceito. Gênio é um espírito peculiar, um guia, um protetor e, nesse sentido, cabe observar, é uma crença que ressurge nas experiências espirituais e ocultistas características da virada do século dezenove para o vinte e que se encontram, dentre outras, na doutrina Teosófica que influencia diretamente o pensamento de Kandinsky. 
Esse espírito, o Gênio, é dado ao homem no seu nascimento e o inspira as ideias originais. Essas ideias não podem ser apreendidas como preceitos para se realizar a obra de arte. Pois, a obra de arte, o que a constitui como tal, seria determinada conceitualmente. Se o gênio não pode ser comunicado, no entanto, suas regras podem ser abstraídas do produto, e este é um ponto importante na aproximação com o espiritual na abstração pictórica, e comunicadas, não como coisa a ser imitada, mas como modelo de imitação característica da obra de arte. Entretanto, este só pode ser comunicado a um outro gênio que é despertado pelo contato com as obras do mestre genial. Se o gênio não pode prescrever a si mesmo, expor seu método, quer dizer, o modo como realiza seu produto, ele pode, entretanto, se expor na obra. A obra é necessariamente o lugar onde o gênio se torna visível. Coisa que não estava prevista no programa kantiano, no que concerne à arte abstrata, a linguagem formal que a estrutura é a marca da genialidade. De fato, o gênio é um nome para as regras do espírito substancializadas na linguagem da pintura abstrata, da maneira pensada por Kandinsky, quer dizer, como manifestação estética de um saber que não se apreende, mas que é revelado, saber das regras da natureza, tal qual o personifica Blawatsky. Um modelo arcaico de conhecimento, que pressupõe a encarnação e o encantamento do espírito, quer dizer, do gênio.

Ressalte-se que em seu livro Ponto, Linha e Plano de 1926, portanto, quinze anos após Do Espiritual na Arte e quando já exercia cargo de professor na Bauhaus de Weimar, Kandinsky elabora um detalhado estudo analítico dos elementos básicos do desenho, das formas gráficas e suas articulações. Nesta obra ele recupera da tradição artística o que ele mesmo denomina de uma ciência da arte. A tese defendida é a de que haveria uma "linguagem" formal da arte, em especial do desenho, fundamento de toda arte plástica. Esta seria mais ou menos aparente a depender das circunstâncias históricas envolvidas. A tarefa levada a cabo em Ponto, Linha e Plano, portanto, é a de revelar e descrever sistematicamente o funcionamento desta "linguagem" depurada de todo elemento externo, excedente à própria "gramática" do desenho. Pode-se pensar que haveria um afastamento em relação às ideias defendidas em Do Espiritual da Arte, na medida em que se pode tomar esta "ciência da arte" como um método. No entanto, o que pretende Kandinsky não é, evidentemente, apresentar uma "fórmula". Ponto, linha e Plano não se organiza como um 
conjunto de prescrições para se realizar uma obra de arte. Este texto é antes, uma tese acerca das formas primeiras, básicas do desenho, e sua organização fenomenológica que Kandinsky separa em interior e exterior (KANDINSKY, 1996, p. 7). Nesse sentido, Kandinsky nos revela o caminho para se compreender uma obra de arte, ou melhor, sua factura onde se revela sua autonomia estética. Nesse sentido também, ele não se afasta da diferenciação pensada por Kant entre as regras que constituem o legado que se apreende nas academias - há sempre algo de mecânico na arte, que lhe é essencial, e este algo é passível de ser ensinado e apreendido por meio de regras - algo mecânico que faz com que uma pintura seja uma pintura, uma escultura uma escultura e assim por diante, e as regras do gênio que constituem efetivamente uma obra de arte. A primeira é a reprodução, correta das regras do fazer e das técnicas, a outra é obra de gênio, onde se exprime as regras da natureza que constitui, portanto, o belo autônomo, isto é aquilo que define efetivamente uma obra de arte (KANT, 1993, p.156). Ponto, Linha e Plano inscreve a autonomia das formas puras do desenho em analogia com as formas puras da natureza, na qual se daria a síntese entre interior e exterior levando a compreensão da ordem maior do Universo.Vê-se, por conseguinte, a aproximação com o Espiritual (KANDINSKY, 1996, p. 103).

Cabe aqui acrescentar um outro elemento, qual seja o de Ideia estética. A concepção de Kandinsky de "obra de arte materialista" se assemelha, em grande medida, à noção de obra sem espírito, segundo a definição de Kant: obra que tem por finalidade não a imitação da ideia estética, mas a reprodução mecânica do agradável, isto é, do meramente sensível. O que a arte tem por fim representar é a ideia estética, ou seja, a contrapartida da ideia da razão, nos termos de Kant. A ideia estética tem esta denominação porque, por sua característica transcendental, aponta para fora dos limites da experiência sensível e nisso se aproxima das "ideias intelectuais" (KANT, 1993). Ela é um produto da faculdade produtiva da imaginação que cria como que uma natureza, a partir da "matéria que a natureza efetiva lhe dá” (KANT, 1993, p. 159). Uma natureza que, embora não seja determinada por conceitos, se aproxima bastante das ideias da razão e, portanto, remete à ideia de liberdade, autonomia e tem a aparência da objetividade. O espírito consiste em um princípio, cuja função é a de tornar visíveis as ideias estéticas, isto é, apresentá-las, na obra de arte, como sua 
própria forma, produzidas segundo suas próprias regras. A arte depende da maneira de se mostrar, de aparecer por meio da correspondência entre a obra ela mesma e a "faculdade produtiva" que aí está em jogo. Se essa correspondência não se realiza, a obra encontra-se reduzida a ser simplesmente um modo de exposição da consequência material e técnica de certas práticas de produção, das quais o espírito é ausente. Quanto à questão do juízo de gosto que é ligado necessariamente ao belo, a arte dele não depende no que concerne à sua definição, posto que é apenas uma faculdade de valorar, segundo Kant, e não produtiva. Pode-se ter uma obra de bom gosto, sem, entretanto, ser obra de gênio.

Diz-se de certos produtos, dos quais se esperaria que devessem pelo menos em parte mostrar-se como arte bela, que eles são sem espírito, embora no que concerne ao gosto não se encontre neles nada de censurável. Uma poesia pode ser verdadeiramente graciosa e elegante, mas é sem espírito. Um discurso festivo é profundo e requintado, mas sem espírito [...] (KANT, 1993, p. 159).

É quase nos mesmos termos que Kandinsky vai se referir à obra de arte que busca um efeito puramente reprodutivo da técnica. Ela pode ser agradável ao gosto, sem ser espiritual. Kandinsky compara seu efeito àquele que resulta da contemplação de uma paleta de cores. Tanto um aspecto quanto outro, limitam a arte ao seu efeito material. No primeiro, o "método que empregará para reproduzir o objeto torna-se, para o artista, o único problema: é o credo de uma arte se alma" (KANDINSKY, 1996, p. 37). No outro, a arte se vê reduzida à sensação fisica agradável que são, por natureza, de curta duração: elas são superficiais e de curta duração, "ela se apaga sem deixar vestígios, mal a alma se fecha" (KANDINSKY, 1996, p. 37).

A alma, o espírito, não é um atributo da arte, aspecto natural da arte, não é tão pouco o que deriva do talento do artista representado pelo puro jogo das faculdades da imaginação sem finalidade. A alma é o espiritual que se concretiza na abstração pictórica, quer dizer, do jogo das faculdades do espírito identificado à ordem da natureza. A alma é esta dinâmica intrínseca ao gênio que se transmite (magicamente, no sentido de Mauss) de um elemento empírico a outro, tornando-os parte de uma correlação que faz do sensível, algo da ordem de uma experiência estética que se não 
é totalmente desprovida de subjetividade, pelo menos pressupõe uma subjetividade compartilhada de maneira objetiva. Ora Kant, procura definir o termo espírito em oposição a tudo o que é do domínio comum do cognitivo: conceito, intuição, entendimento, etc., permanecendo, entretanto, em uma relação de analogia com a ideia, com os conceitos.

Como bem percebeu o teórico e crítico da arte americano Clement Greenberg, a quem muito se deve a defesa das teses kantianas como fundamento teórico ao formalismo na arte, na experiência estética, o sujeito passa a ser tão objetivo quanto sua razão. Ainda que não seja o sujeito transcendental do conhecimento, ele é necessariamente universal. Na experiência estética há como que um distanciamento do sujeito particular com suas características psicológicas e práticas individualizantes norteadas por interesses, o que para Kant vai no sentido contrário ao juízo estético que é desinteressado, posto que sem conceito e finalidade que o determinem. Na experiência estética: "O indivíduo passa a ser tão objetivo quanto em seu raciocínio, o que igualmente requer um distanciamento em relação a este Eu particular" (GREENBERG, 2002, p. 56). O conteúdo, sua forma abstrata, por ser obra do gênio, o espiritual, é necessariamente objetivo, universal, e por ser desinteressada, desligada dos limites de uma razão instrumental materialista, visa uma outra razão: aquela das regras da natureza e da liberdade de vontade, ou seja do espírito livre. Nesse sentido, como afirma Jean-Paul Bouillon no prefácio de Olhar sobre o passado, misto de ensaio teórico e autobiográfico de Kandinsky, a abstração pictórica é em grande parte um projeto mítico, ideológico e com pretensões religiosas e morais. A arte serve e consiste em um sistema moral e moralizador, único capaz de revelar, pela experiência estética das leis do gênio, a lei moral interior que cada um deve seguir. Desta forma o próprio texto de Kandinsky torna-se indissociável de sua obra pictórica e mesmo a justifica para além do momento histórico como projeto metafísico e ético. "Quando se substitui o estudo das relações dialéticas por uma verdadeira teologia da obra de arte, esta acaba se tornando, mais uma vez, apenas uma paráfrase daquele que se converte em seu modelo, em vez de ser o objeto de sua análise" (BOUILLON in KANDINSKY, 1991, p.47).

O espírito é a forma absoluta, espiritual, moral da arte, que lhe dá o conteúdo, enquanto a forma material, dada por sua resolução técnica, é relativa e restrita aos materiais e à experiência sensível, portanto, subjetiva. 
"O essencial na questão da forma, é saber se ela nasceu de uma necessidade interior ou não" (KANDINSKY,1996, p.120). Quando a forma é dada pelas regras do gênio, quando este é o conteúdo da arte e tem por origem o livre jogo da faculdade de imaginação, livre jogo que se torna visível na composição abstrata, então ela está de acordo com a necessidade interior e cumpre sua função espiritual e moralizadora. Essa necessidade interior é a regra moral que tem por horizonte o conceito de liberdade; a vontade livre, autônoma e a liberdade de criar estética se encontram numa relação de analogia, confundidas que estão com o poder mágico do espiritual, cujas características Kandinsky distingue na arte abstrata, como sendo uma grande liberdade que nos permite ouvir a voz do espírito e que em última instância se manifesta na expressão estética. A arte, como pensava Kant, no momento em que se afasta do simples prazer agradável, deve estar em uma disposição a fins no juízo da razão. Pode-se grosso modo, encontrar aí ecos da formulação kantiana, por intermédio da qual, pode-se também compreender o espiritual de Kandinsky como seu herdeiro.

A ligação entre arte e moral na abstração corresponde àquela simbólica indicada por Kant entre belo e moral. Se o belo na arte é fruto do gênio, quer dizer das regras da natureza como regras da arte, e este é o conteúdo da arte, e se o belo, por seu caráter natural, é necessário e compartilhado universalmente no juízo estético, este, por um assentimento universal regido por um principio de liberdade é simbolicamente análogo ao moralmente-bom. Uma marca disso seria o uso de adjetivos morais em juízos estéticos. Assim sendo, como afirma Kant: "o gosto torna, por assim dizer, possível a passagem do atrativo dos sentidos ao interesse moral habitual" (KANT, 1993, p.199). Disso depende que o livre jogo da faculdade da imaginação, faculdade produtiva, esteja conforme a fins do entendimento, ou seja, que não esteja contraposta à razão.

Gostaria de finalizar com duas observações. Primeiro, quanto à arte abstrata, a razão estaria reduzida à sua capacidade de refletir o espiritual. Ela se exprimiria na linguagem formal da abstração, que por sua vez seria a imagem de uma "razão" mágica, cujas regras, também elas sobrenaturais, espirituais e divinas, regem a natureza identificada a um princípio moral. Por conseguinte, se a pintura abstrata se considera livre de toda "natureza", não é menos verdade que uma outra "natureza", derivada de uma necessidade moral interior, subsiste e constitui o valor ontológico da obra 
de arte. Segundo, essa natureza do gênio, do espírito que nas palavras de Adorno, ao procurar escapar a uma estetização da excitação sensível, puramente ornamental, material e técnica, ganha autonomia, desaparece na materialidade que ela tenta espiritualizar. Ela se perde ao tentar despojar a obra de todo peso sensível, posto que para se realizar, paradoxalmente, não pode prescindir de um meio material e técnico, portanto, determinado por finalidades. O espiritual acaba por se fixar no material "nu", no "puro e simples ente" (ADORNO, 2002). Este espírito implica uma sensibilidade asséptica e é por isso apenas "glorificada por ela mesma", quanto mais se tenta espiritualizar a arte, mais o espiritual dela se afasta.

\section{Referências bibliográficas}

ADORNO, T.W. 2002. L'art et les arts. Paris: Desclée de Brouwer.

GREENBERG, C. 2002. Estética doméstica. São Paulo: Cosac e Naify.

KANT, I. 1993. Crítica da faculdade do juízo. Rio de Janeiro: Forense Universitária.

KANDINSKY,W. 1991. Olhar sobre o passado. São Paulo: Martins Fontes. 1996. Do espiritual na arte e na pintura em particular. São Paulo: Martins Fontes. 1996. Ponto, linha e plano. Lisboa: edições 70.

MAUSS, M. 2003. Sociologia e antropologia. São Paulo: Cosac e Naify. 